2. PROBLEMAS CONSTITUCIONALES DE LA REUNIFICACIÓN ALEMANA

JUAN COTARELO GARCÍA 


\section{SUMARIO}

Introducción.-I. Dimensión de derecho Internacional.-II. DimenSiÓn CONSTITUCIONAL.-1. Antecedentes.-2. La posición del art. 146 en la LF.-3. Inderogabilidad del art. 146 LF n.v.-3. La tramitación parlamentaria del Tratado de Unificación (TU) y la versión final del art. 146 LF.-5. Propuesta de solución al problema del art. 146 LF n.V. 
Revista de Derecho Político, núm. 40, 1995, pp. 29-55

\title{
2. PROBLEMAS CONSTITUCIONALES DE LA REUNIFICACIÓN ALEMANA
}

POR

\author{
JUAN COTARELO GARCIAA
}

INTRODUCCIÓN

El proceso reunificador de Alemania efectuado durante 1990 ha implicado aspectos de derecho internacional y de derecho constitucional nacional. La dimensión internacional interviene al tratarse, en esta reunificación, de la unificación de dos Estados independientes (la RFA y la RDA), lo que siempre ha sido una cuestión de derecho internacional ". Aunque la RFA siempre se consideró la continuadora jurídica del "Deutscher Reich " ${ }^{2}$, bien que su condición territorial minorada sólo tolerase una

1 FroweIN,J. A., "Rechtliche probleme der Einigung Deutschlands", en Europa-Archiv, 1990/7, pág. 233.

2 De acuerdo con el protocolo de Londres de 23 septiembre 1944, y en aplicación del principio de derecho internacional que niega toda validez a los cambios de fronteras operados por la fuerza, la Alemania ocupada por las potencias vencedoras era la integrada por las fronteras de 31 de diciembre de 1937. En sucesivas conferencias de las potencias vencedoras, este territorio, inicialmente alemán, experimentó reducciones para adaptarlo a la situación política consolidada después de 1945. En el "Protocol of the Proceedings of the Berlin Conference», más conocido como Acuerdo de Postdam, se fijó la línea determinada por los ríos Oder y Neise como límite oriental de la zona alemana bajo ocupación soviética (más tarde RDA). Los territorios alemanes al oeste de la línea Oder-Neise, exceptuando Prusia oriental, es decir, Pomerania y Silesia, quedaron bajo administración directa de Polonia. La parte norte de Prusia oriental quedó bajo dominación soviética. Consiguientemente, las manifestaciones de la RFA relativas a su identidad con el "Deutscher Reich" (ver, por ejemplo, STCF 36, 1, 16), han de entenderse no sólo referidas a las dimensiones más reducidas de la Alemania a 31 de diciembre de 1937, sino a las subsiguientes minoraciones territoriales introducidas por las potencias vence- 
"identidad parcial» con él (STCF 36, 1, 16), el obligado desconocimiento diplomático de la RDA a que ello la obligaba, perdió ya todo fundamento desde la resolución TESO del Tribunal Constitucional Federal (TCF) de octubre de 1987. Desde este momento la tesis de los "dos Estados en Alemania" dejó de ser una más de las consignas del Partido Comunista de la RDA (SED). A partir de entonces la RFA no pudo seguir pretendiendo ser la "identificación parcial" de toda Alemania. Tan sólo era una parte de ella, del mismo modo que, con independencia de sus carencias estructurales, también lo era la $\mathrm{RDA}^{3}$. Reconocimiento que se hizo imprescindible una vez que el levantamiento popular en la RDA evidenció la condición estatal fragmentaria de la RFA, integradora de una sola parte del pueblo alemán $y$, consiguientemente, provisional hasta la reconstitución de la unidad estatal de todo el pueblo alemán 4 .

La dimensión constitucional de la cuestión aparece cuando vemos que la unificación de los dos Estados es, simultáneamente, la reunificación nacional alemana, efectuada según los procedimientos previstos para ello en la Ley Fundamental (LF) de la RFA. Es, pues, una cuestión de reintegración estatal y, como tal, una cuestión medular del derecho constitucional ${ }^{5}$.

\section{DIMENSIÓN DE DERECHO INTERNACIONAL}

La situación política creada por los acontecimientos acaecidos en la RDA durante 1990, y que culminaron el 17 de junio con la propuesta de la Cámara Popular en favor de la adhesión a la RFA, tenia desde la LF distintas formas de recepción constitucional. Los arts. 23 y 146 de la LF ofrecían mecanismos distintos con los que abordar, desde la RFA, la voluntad reunificadora de la población de la RDA. La generalidad de la opinión experta pensaba que ambos caminos eran jurídicamente viables, aunque

doras en beneficio de Polonia y de la Unión Soviética (ver FroweiN, J. A., "Die Rectslage Deutschlands und der Status Berlin", en BendA/MalHOFER/Nogel, eds.: Handbuch des Verfassungsrechts, Berlín, 1984, vol., págs. 31, 34 y 47).

3 Ver RÖPER, E., "Notwendige Kooperation des bisherigen DDR-Länder in Vereinten Deutschland", en Recht und Politik, 1990/3, pág. 142.

"Ver ISENSEE, J., "Verfassungsrechtliche Wege zur deutschen Einheit", en Zeitschrift für Parlamentsfragen, julio 1990, pág. 309.

5 Ver Frowein, J. A., op. cit., nota 1, pág. 233. 
el contenido y las consecuencias jurídico-políticas de cada uno de ellos eran muy diferentes ${ }^{6}$. Aunque aparentemente contradictorios, ambos artículos ( 23 y $146 \mathrm{LF}$ ) estaban en realidad previstos para situaciones diferentes ?. Los arts. 23 y 146 LF respondían a la voluntad de mantener procedimientos diferenciados, con los que reaccionar frente a situaciones históricas y políticas de distinta entidad ${ }^{8}$. Sin embargo, sí parece posible en algunos casos la utilización de ambos procedimientos para el tratamiento de una misma situación política, siempre que su complejidad no sólo admita la aplicación de ambas disposiciones, sino que lo exija necesariamente. En este sentido, FROWEIN y HÄBERLE, entre otros autores, mantuvieron la inexistencia de impedimentos para la aplicación combinada de los artículos 23 y 146 LF en el proceso de reunificación alemana ${ }^{9}$, aunque la combinación propuesta se resolvía en la utilización prácticamente exclusiva del art. 23 LF, para alcanzar la complitud territorial alemana y proceder después a la derogación del art. 146 LF por simple reforma constitucional, con lo que la contribución de éste último a la reunificación consistiría en su derogación.

En ello consistía la línea de acción, por la que la mayoría conservadora del Gobierno federal de coalición deseaba realizar la reunificación, aunque afortunadamente las exigencias del procedimiento parlamentario (mayoría de 2/3 para proceder a la reforma constitucional) impidieron lo que, a todas luces, hubiese sido un manifiesto fraude de Constitución. Una vez la vía procedimental bloqueada, la mayoría de gobierno optó por la solución consistente en mantener en la Constitución de la Alemania unida el art. 146 LF v.a. (LF, versión antigua), provisto de una addenda que no afecta al significado originario del artículo. En suma, un art. 146 LF v.n. (versión nueva). La salida buscada refleja tan alto grado

- WeIs, H., "Verfassungsrechtliche Fragen in Zusammenhang mit der Herstellung der staatlichen Einheit Deutschlands», en Archiv des öffentlichen Rechts, 1991/1, pág. 2.

7 El art. 23 LF enumera los territorios sobre los que extiende su validez la LF, posibilitando su ampliación a otros territorios alemanes que decidan adherirse a la RFA. El art. 146 LF, en cambio, invoca la voluntad de aprobar una nueva Constitución, derogatoria de la LF, una vez que la unidad y libertad del pueblo alemán sean una realidad.

${ }_{8}$ Ver Maunz/Düring, "Grungesetz Kommentar», art. 146. El art. 23 LF contemplaba el ámbito territorial "abierto» de validez de la LF, mientras que el art. 146 LF, por el contrario, alude a la vigencia temporal y provisional de la misma. Por todo ello, y con independencia del paralelismo que pudiese establecerse entre ambas disposiciones, nunca podría aplicarse el procedimiento de la una a la situación para la que estaba prevista la otra.

s Constituyó lo que se denominó la "tercera vía". Ver Frowern, J. A., op. cit., nota 1, pág. 234; HäвERlE, P., "Verfassungspolitik für die Freiheit und Einheit Deutschlands", en Juristische Zeitung, 1990, pág. 359 s. 
de indecisión, que ha generado una de las situaciones más equívocas del moderno panorama constitucional.

Desde una estricta óptica de derecho internacional, la unificación alemana nos sitúa ante la absorción de un Estado (RDA) por otro (RFA), para lo que el art. 23 LF proporciona la cobertura constitucional y el Tratado de Unificación (TU) -aprobado por los Parlamentos de ambos Estados alemanes en septiembre de 1990- la cobertura jurídica del proceso de absorción (principios generales de incorporación, derogaciones temporales o permanentes de la $L F^{10} \mathrm{y}$ del derecho federal aplicable también en la ex-RDA, períodos transitorios de adaptación legislativa... Es una situación que, sin responder a regla alguna de derecho internacional aunque sí a una praxis generalizada, se soluciona manteniendo inalterada la identidad jurídica del Estado receptor (RFA) cuya extensión territorial se ampliará en proporción al territorio del Estado absorbido (RDA), que desaparece como Estado. En el proceso unificador, la RDA sucumbió como sujeto de derecho internacional, planteándose la cuestión de la sucesión estatal únicamente para éste último ". La condición jurídico-internacional de la RFA - cuyo territorio se amplía ahora a la ex-RDA - no se ve modificada. El art. 23 LF faculta a la RFA para extender la validez de la LF al territorio incorporado, con lo que la Alemania unida se encuentra bajo un mismo estatuto

10 En la medida en que la adhesión de la RDA suponía modificaciones permanentes de la LF —como, por ejemplo, el Preámbulo de la LF, o el propio art. 23 LF-, los artículos correspondientes del Tratado de Unificación debieron ser aprobados por mayorías de $2 / 3$ de cada una de las Cámaras de la RFA. Ver Fromont, M., "Le Droit allemand depuis le Traité de l'Union du 30 août 1990", en Revue du Droit Public, 1993/1, pág. 81.

"Ver "Veroffentlichungen der Vereinigung der Deutschen Staatsrechtslehrer" (VVDStRL), n. 49, Berlín, 1990, donde se recogen las ponencias y el debate posterior del Congreso extraordinario de los Profesores de Derecho Político celebrado en Berlin en abril de 1990 sobre el tema "La situación constitucional alemana". Los ponentes de derecho internacional (FroweIN y RANDELZHOfER) coincidieron en que, al haberse efectuado la unificación alemana por el procedimiento de «incorporación", los tratados del Estado receptor extienden su vinculación al territorio del Estado incorporado, mientras que los de éste último decaerían como obligaciones internacionales frente al Estado receptor. Los arts. 11 y 12 del TU regulan ambos aspectos: el art. 11 TU establece: "... Los tratados y acuerdos internacionales de los que es parte la RFA, comprendidos aquellos que la hacen miembro de organizaciones o instituciones internacionales, conservan su vigencia, de forma que los derechos y obligaciones de ellos derivados conciernen también al territorio mencionado en el art. 3 (ex-RDA)...". A su vez, el art. 12 TU establece que "los tratados internacionales de la RDA habrán de ser examinados conjuntamente con los responsables de la RDA, en el marco de la realización de la unidad alemana, a fin de regular o constatar su mantenimiento en vigor, su adaptación o su caducidad...". 
jurídico (la LF v.n.), coincidente, salvo modificaciones puntuales, con la antigua $L^{12}$.

Por el contrario, si la unificación se hubiese producido ab initio por la vía del art. 146 LF, se habría suscitado en toda su agudeza el problema de la sucesión estatal en lo tocante a los compromisos y obligaciones internacionales de cada uno de los dos Estados anteriores, cuya simultánea desaparición debería quedar jurídicamente compensada ${ }^{13}$. No obstante, también hubo autores que sostuvieron el criterio de la inalterabilidad de la RFA, aunque la unificación se hubiera efectuado por el art. 146 LF. Se argumentó que la "estatalidad alemana», jurídicamente establecida en el "Deutscher Reich» de 1867 y mantenida a lo largo de los últimos 130 años de vicisitudes territoriales, tiene su continuidad jurídica en la RFA ("parcialmente idéntica" con el "Deutscher Reich»), sin que este sujeto de derecho se hubiese visto afectado, cualquiera que hubiese sido el procedimiento unificador seguido ${ }^{14}$. En todo caso, a la inevitable inseguridad jurídica que esta via unificadora hubiera suscitado habría de sumarse lo largo y complicado de su procedimiento. Iniciar la unificación estatal por el art. 146 LF habría exigido plebiscitos separados en la RDA y en RFA, antes de proceder a unas elecciones conjuntas en ambos Estados para la Asamblea constituyente, cuya labor daría fin, simultáneamente, a la unificación y a la reunificación. La duración y dificultades inherentes a esta vía hizo que en ningún momento se plantease seriamente la opción de utilizar directamente $a b$ initio el art. I46 LF. El coste político de una reuni-

12 No parece necesario aludir a las ventajas derivadas de haber encauzado de esta forma el proceso unificador. Al mantener el Estado resultante la condición jurídica inalterada de la antigua RFA, tampoco se alteró el esquema occidental de defensa, al no variar la situación de la RFA como miembro de la OTAN. Asimismo encontró una solución rápida y elegante la cuestión referida a la Comunidad Europea. Alemania mantiene invariada su condición de miembro de la CE, en las mismas condiciones que la antigua RFA, al no haber exigido la ampliación de voto correspondiente a su ampliación territorial y poblacional en el Consejo de Ministros (ver Fromont, M., "Le Droit allemand depuis le Traité d'Union du 30 août 1990", en Revue du Droit Public, 1993/1, págs. 83 ss.).

13 Ver ISENSEE, J. A., "Verfassungsrechtliche Wege zur deutschen Einheit", en Zeitschrift für Parlamentsfragen, julio 1990, pág. 318.

14 Ver FroweIN, J. A., "Deutschlands aktuelle Verfassungslage", en VVDStRL n.o 49, Berlín, 1990. MeYeR, H. («Diskussionsveranstaltung der Deutschen Vereinigung für Parlamentsfragen", en Zeitschrift für Parlamentsfragen, 1990/2) también sostiene la inalterabilidad jurídico-internacional de la RFA, cualquiera que sea el procedimiento unificador seguido. Es una tesis a la que, con matices, también parece sumarse ISENSEE cuando afirma que el procedimiento del art. $146 \mathrm{LF}$ para la unificación no conduce a un nuevo Estado, sino únicamente a una nueva Constitución (ver ISENSEE, J., "Deutschlands aktuelle Verfassungslage", en VVDStRL n. 49, Berlín, 1990; ibidem, "Verfassungsrechtliche Wege zur deutschen Einheit", en Zeitschrift für Parlamentsfragen, 1990/2. 
ficación, directamente efectuada a través del art. $146 \mathrm{LF}$, hubiese sido tan elevado, que las posibilidades de su utilización para ese fin nunca fueron muy elevadas ${ }^{15}$.

Por el contrario, la utilización del art. 23 LF ha permitido eludir el interregno jurídico-internacional, durante el proceso de complitud territorial de Alemania, al operar sobre el piñón fijo de la inalterabilidad de la RFA como sujeto de derecho internacional. El resultado del proceso unificador ha sido el mantenimiento de la identidad (igualmente "parcial») de la Alemania unificada con su antecesor jurídicamente posible: el "Deutscher Reich" de 1867, exceptuadas las regiones alemanas al este del Oder-Neise, cuya soberanía ha quedado definitivamente transferida a Polonia y Rusia ${ }^{16}$.

\section{DIMENSIÓN CONSTITUCIONAL}

\section{Antecedentes}

La dimensión constitucional del proceso se centra en el cumplimiento de las exigencias que, para la reunificación alemana, establece el documento constitucional por el que se ha operado la reunificación de los dos Estados alemanes, la Ley Fundamental de la RFA.

15 Ver FroweIN, J. A., "The Reunification of Germany", en American Journal of International Law, 1992, pág. 154, nota 12.

16 Corresponde, como vimos en nota 2, a las reducciones sufridas por el perímetro territorial de la Alemania de 1937, operadas por las potencias aliadas en el Acuerdo de Postdam de agosto 1945, el Tratado de Gorlitz de julio de 1960 y el Tratado de Varsovia de diciembre de 1970. Sin embargo, debido a lo jurídicamente discutible de las modificaciones de fronteras introducidas por potencias vencedoras, todos los cambios introducidos en las fronteras alemanas de diciembre de 1937 por las potencias aliadas eran jurídicamente cuestionables. La opinión doctrinal alemana parece unánime, respecto a negar a aquellos tratados la condición de títulos jurídicos válidos para la modificación constitutiva de las fronteras alemanas de 31 de diciembre 1937. Consiguientemente, el reconocimiento del Oder-Neise como frontera entre Polonia y Alemania precisaba de un acto jurídico formal de la Alemania unificada (ver GORNIG, G., "Deutschlands aktuelle Verfassungslage", en Der Staat, vol. 29, 1990/3, págs. 373 y ss.). Dicho acto se ha reducido al enunciado contenido en el art. 1 del TU, en el que se establece que la Alemania unida se compone de los territorios de ambos Estados alemanes, incluido Berlín, y que ulas fronteras exteriores derivadas de ello son definitivas". 
El Preámbulo de la LF establece con toda claridad la naturaleza provisional del documento que prologa. La validez y vigencia de la LF, de acuerdo con el Preámbulo y con el sentido de los artículos 23 y 146 LF, queda vinculado a la realización de unos objetivos, cuyo cumplimiento señala la desaparición de los hechos impeditivos del ejercicio de una potestad constituyente del pueblo alemán. La transitoriedad de estos hechos se ha cubierto en derecho con un documento constitucional provisional, al que sus creadores dieron en 1949 el nombre de Ley Fundamental ("Grundgesetz"). Por tanto, la continuidad de la LF, más allá de las condiciones de hecho que la hacian inevitable, parece privarla de toda legitimidad ${ }^{17}$.

Las razones que impulsaron al Consejo Parlamentario y a la Convención Constitucional alemanes en 1949 a elaborar un provisorium tenían sólo secundariamente que ver con la división en dos de Alemania (las tres zonas bajo control aliado-occidental y la zona bajo control soviético). Decisivo para el carácter provisional de la Lf fue, más bien, la situación de tutela a que se encontraban sometidos los órganos constituyentes, sometidos a las directivas materiales y a la reserva de aprobación final por las potencias de ocupación. Pero también a la consciente carencia de legitimación democrática de los gremios constituyentes del año 1949, como atestiguan las intervenciones de C. SCHMID en las sesiones plenarias del Consejo Parlamentario. Por estas mismas razones, el Consejo Parlamentario decidió no someter a referéndum la LF, en contra de la opinión de la potencias aliadas de ocupación ${ }^{18}$. La carencia de sanción popular de la LF se revelaba coherente a la naturaleza provisional con la que había sido concebida y elaborada. El referéndum hubiese conferido a la LF una plenitud que sus creadores habian desechado deliberadamente. El informe final de la Convención constitucional lo expresaba con claridad:

"Dado que la LF no surge de la libre voluntad configuradora del pueblo alemán, sino que ha debido acoplarse a vías preestablecidas, se ha aceptado su decadencia y desaparición tan pronto como entre en vigor una Constitución aprobada por la libre autodeterminación del pueblo alemán" ${ }^{19}$.

17 Ver Storost, U., «Das Ende der Übergansszeit», en Der Staat, vol. 29, 1990/3, pág. 321; KIRCHHOF, P., "Die Identität der Verfassung in uhrer unabänderlichen Inhalt", en ISENSEE/KIRCHHOF (eds.), Handbuch des Staatsrechts der BRD, 1987, vol. I, aptdo. 19.

12 Ver Wagner, J. V. (compldr.), "Das Parlamentarische Rat. Akten und Protokolle", vol. 2, Vorgeschichte, 1975, pág. 32.

19 BuCher, P. (compldr.), "Das Parlamentarische Rat. Akten und Protokolle», vol. 2, Verfassungskonvent auf Herrenschimsee, 1981, pág. 577. 
La condición provisional de la LF quedó fijada en su texto, concretamente en el art .146 LF. También se expresaron entonces opiniones en contra del art .146 LF, por considerar que sólo expresaba una obviedad, a saber, que toda Constitución mantendrá su vigencia, mientras el soberano - es decir, el pueblo- no disponga otra cosa. Pero las objeciones al art. 146 LF no prosperaron, ya que - como sostuvo permanentemente C. SCHMID - el art. 146 LF tenía por finalidad no la mera afirmación del poder constituyente del pueblo, sino la garantía de «que la Constitución alemana definitiva surgiría de modo originario, y no por vía de reforma de la $L F »{ }^{20}$.

\section{La posición del art. 146 en la LF}

En la discusión doctrinal en torno a la reunificación alemana predominó la tendencia a hacer extensiva la articulación jurídico-internacional a la dimensión constitucional del proceso. Se argumentó que la derogación de la LF por una nueva Constitución, en cumplimiento de lo preceptuado en el art. $146 \mathrm{LF}$, no tenía necesariamente que suponer la creación de un nuevo Estado, ya que "la cuestión de bajo qué condiciones una Constitución cesa en favor de otra, sólo tiene sentido si se mantiene la identidad jurídica del Estado" ${ }^{21}$. Ciertamente, como ya mantuvo ANSCHÜTZ en 1919, la existencia jurídica de un Estado no depende de su Constitución. Ni siquiera se cuestiona la permanencia de aquél en el caso de una revolución, tanto menos entonces por el cambio de Constitución. El Estado es precisamente el continuum de la unidad política, mantenida a través y por encima de los cambios de sus formas políticas ${ }^{22}$.

Todo ello es teóricamente inobjetable desde la óptica de derecho internacional, en el que lo esencial es la inalterabilidad de la subjetividad jurídica de uno de los Estados en el proceso integrador, con independencia de los cambios territoriales que puedan suceder. Es, por lo práctico, además, muy conveniente. Pero es un esquema no siempre aplicable en

${ }^{20}$ SCHMid, C., en Wiederin, E., "Verfassungsgebung im wiedervereignuiten Deutschland", Archiv des öffentlichen Rechts, 1992/3, pág. 423.

21 Ver ISENSEE, J., op. cit., nota 4, pág. 319.

${ }^{22}$ Sobre la relación entre Estado y Constitución, ver KuRz, H. (ed.), Volkssouveränität und Staatssouveränität, Darmstadt, 1970; ISENSEE, J., Staat und Verfassung, en ISENSEE/KIRCHHOF, Handbuch des Staatsrechts der BRD, 1987, vol. I. 
derecho constitucional $y$, en ocasiones -como en el caso presente-, hasta resulta incompatible con él. En derecho constitucional material no existe, por un lado, el Estado $y$, por el otro, su Constitución como algo desgajable de él. Lo que existe es el Estado constitucional, y en este caso lo que existía era el Estado transitorio de la LF. La provisionalidad constitucional alemana no permitía hablar de "unidad estatal» como algo independiente de su "unidad constitucional». Ambos momentos, aunque analíticamente separables, eran partes indisociables del proceso jurídico-político de reunificación alemana. Involucrar al art. 1.46 LF en el contexto argumentativo jurídico-internacional, sólo contribuye a desnaturalizar su contenido, en una confusión interesada de las dimensiones unificadoras y reunificadoras del proceso ${ }^{23}$.

En derecho constitucional -a diferencia del derecho internacional- corresponde al Estado integrador modificar su derecho constitucional para adaptarlo al nuevo hecho resultante de la integración. El proceso puede suponer, para el Estado incorporador, tan sólo una modificación ocasional (o incluso ninguna modificación, como ocurrió con la incorporación de Sarre a la RFA en 1956) ${ }^{24}$, o, por el contrario, una modificación sustancial, como en el caso de la adhesión de la RDA a la RFA. Debido a la significación que, para la reunificación alemana, ha tenido esta última adhesión $\mathrm{y}$, además, debido a que en este caso el territorio incorporado era un Estado soberano, el procedimiento seguido no podía

${ }^{23}$ La LF contemplaba -y después de la reunificación sigue contemplando- dos Estados: el Estado constitucionalmente institucionalizado por la LF y el Estado previsto en el art. $146 \mathrm{LF}$, de acuerdo con la intervención de A. ADAmietz en la "Diskussionveranstaltung der Deutschen Vereinigung für Parlamentsfragen», en Zeitschrift für Parlamentsfragen, julio 1990, pág. 346.

${ }^{24}$ La integración de Sarre en la RFA se hizo en 1956 a través de dos instrumentos jurídicos: a) uno de naturaleza internacional, el Tratado de Sarre de octubre de 1956 entre Francia y la RFA, por el que Francia aceptaba la entrada en vigor de la LF y del derecho federal alemán en Sarre desde enero de 1957; b) otro de naturaleza nacional, la Ley de Incorporación de Sarre de 23 de diciembre de 1956 -ley ordinaria aprobada por el Parlamento alemán-, por la que se hacía efectiva la Declaración de Adhesión a la RFA del Parlamento de Sarre de 14 de diciembre de 1956 (ver WeIs, $H_{\text {., }}$ "Verfassungsrechtliche Fragen im Zusammenhang mit der HersteIlung der staatlichen Einheit Deutschlands», Archiv des offentlichen Rechts, 1991/1, pág. 11).

La Ley de Incorporación -cuyo contenido había sido acordado conjuntamente por Sarre y la RFA - regulaba la gradual aplicación de la LF y del resto del derecho federal alemán a Sarre. La Ley contenía numerosas medidas de adaptación legislativa, para facilitar la incorporación, pero no supuso modificación alguna de la LF. A consecuencia de ello, bien que Sarre sea un Land más de la RFA desde 1 de enero de. 1957 (Sarrland), no se mencionaba ni en el Preámbulo ni tampoco en el art. 23 LF (ver Fromont, M., "L'Union de l'Allemagne dans la liberté 1989-1990", Revue du Droit Public, 1991/1, pág. 144). 
ser el mismo que para Sarre ${ }^{25}$, independientemente de que ambas integraciones se efectuasen al abrigo del art. 23 LF.

La adhesión de la RDA no se efectuó, como en el caso de Sarre, por medio de una ley ordinaria, sino por un tratado entre ambos Estados, el Tratado de Unificación (TU) de 31 de agosto de 1990. Tratado en el que se recogía la gradualidad de aplicación de la LF y los regímenes transitorios de aplicación del derecho federal al territorio de la ex-RDA, y que fue aprobado por los Parlamentos de ambos Estados el 20 de septiembre de 1990. En el caso del Parlamento de la RFA, aquellos artículos del TU derogatorios de la LF fueron aprobados por mayoría de $2 / 3$ de cada Cámara legislativa, como preceptúa el art. 79.2 LF para la reforma de la LF. Por consiguiente, la aprobación del TU por la RFA supuso ipso iure la reforma de la LF en aquellos aspectos expresamente señalados en el Tratado.

EI TU especificaba qué aspectos de la LF entrarian automáticamente en vigor, en el territorio de la ex-RDA, con la aplicación del TU, así como cuáles lo harían gradualmente o no entrarían nunca en vigor (arts. 3,6 y 7 TU). Igualmente contenía el TU las reformas de la LF (art. 4 TU), así como el alcance y rango del derecho federal que entraría en vigor en el territorio de la ex-RDA, y el derecho de la RDA que mantendría su vigencia (arts. 8 y 9 TU). EI TU se revela entonces como un verdadero tratado constitucional y legislativo y, aunque efectuado al abrigo del art. 23 LF, no hubiese precisado de dicha cláusula constitucional para su elaboración, ya que el propio Tratado establece el vínculo normativo entre la adhesión y las consecuencias jurídicas de ella derivadas para ambas partes ${ }^{26}$. No obstante, el TU ha quedado entendido como una aplicación concreta del art. 23 LF, en la medida en que afecta a la reintegración territorial alemana en los límites de diciembre de 1937 y, al mismo tiempo, es el cumplimiento de la invocación contenida en el Preámbulo en pro de conseguir aquella reintegración. Pero, a su vez y por imperativo político internacional, la adhesión de la RDA quedaba entendida como conclusión

${ }^{25}$ Las diferencias existentes entre la incorporación de Sarre y la adhesión de la RDA son considerables. Ya SCHEUNER manifestaba que un recto entendimiento del art. 23 LF debería reducir su aplicación a los casos de incorporaciones de pequeños territorios (Sarre, Berlín...). Es decir, para aquellos casos en los que el resultado no colmase el supuesto habilitante recogido en el art. 146 LF (ver SCHEUNER, U., "Art. 146 LF. und das Problem der verfassungsgebenden Gewalt», DÖV, 1953, en KuRz, H., ed., Volkssouveränität und Staatssouveränität. Darmstadt, 1970, pág. 289).

${ }_{26}$ Un Tratado de esta naturaleza podría haberlo suscrito la RFA con cualquiera de sus Estados vecinos, fuese o no antiguo territorio alemán (ver WEIS, H., op. cit., nota 23, pág. 13). 
y culminación de aquella reintegración territorial, como efectivamente se recoge en el art. 1 del TU, por el que las fronteras resultantes de la adhesión de la RDA se consideran definitivas. Declaración que, en virtud de la capacidad reformadora de la LF con que la mayoría de 2/3 de aprobación por el Parlamento de la RFA dota a ciertos artículos del TU, ha pasado a formar parte del art. 23 LF.

Una vez efectuadas las fases de adhesión previstas en el TU, se producia aquel supuesto (unidad y libertad del pueblo alemán) que el art. 146 LF consideraba $-y$ considera - como habilitante para crear una constitución que, derogando a la LF, ponga fin a la provisionalidad constitucional alemana. Queda, por tanto, un último paso por dar, debido a que la complitud territorial de Alemania, alcanzada por la vía del art. 23 LF, no ha puesto fin a la provisionalidad de su régimen constitucional, como ya anticipara SCHMID ante el pleno del Consejo Parlamentario en mayo de 1949: “El ámbito territorial de validez de la LF no está cerrado. Cualquier territorio alemán puede adherirse a él. Pero tampoco la adhesión de todos los territorios alemanes podrá hacer de la LF la Constitución de toda Alemania. Ésta sólo existirá cuando el pueblo alemán haya determinado libremente la forma y contenido de su existencia polítican ${ }^{27}$. Sin embargo, también es cierto que la voluntad del legislador es sólo uno de los instrumentos interpretativos - y no el más decisivo- del derecho positivo. Determinante para la interpretación del derecho positivo es la voluntad "objetivada" en la norma, sin que, para su adecuado entendimiento, la voluntad del legislador histórico sea algo más que una referencia circunstancial. Corresponde entonces al contenido del art. $146 \mathrm{LF}$, situado en el contexto sistemático de la LF y en la mudanza de sentido que la reunificación haya podido imprimir a dicho contenido, revelar su significado actual.

En este orden de cosas, al calor de la relación existente entre unidad estatal y unidad constitucional, un importante sector doctrinal argumentó en favor de vincular la complitud territorial (estatal) con su correlativa unidad constitucional. Para ello entienden que, una vez alcanzada la unidad estatal, una vez conseguida la meta invocada en el art. $146 \mathrm{LF}$ -aunque por otros medios distintos a los previstos en su enunciado-. se produce la decadencia automática de dicho artículo, en virtud del prin-

27 C. Scihmid, en Wagner, J. V. (compldr.), Der Parlamentarische Rat. Akten und Protokolle, vol. 2, Vorgeschichte, 1975, pág. 172.

${ }_{28}$ Principio cuya aplicación, incluso sus propios defensores, limitan a casos muy excepcionales: aquellos en los que la aplicación de una ley en el presente condujese a resultados absurdos o descabellados. 
cipio general "cessante ratione legis cessat lex ipsa" ${ }^{28}$. Se viene a decir que la derogación de la LF, prevista en el art. $146 \mathrm{LF}$, sólo es vinculante cuando la reunificación se produce al amparo de dicho artículo, y que, al haberse producido por otra vía - concretamente, por la del art. 23 LF-, decae la finalidad justificativa del art. 146 LF. En conclusión, el proceso de reunificación canalizado por al art. 23 LF produce la obsolescencia y decadencia automática del art. $146 \mathrm{LF}$, con lo que la LF deviene ipso iure la Constitución definitiva de la Alemania unida ${ }^{29}$. Esta interpretación del art. $146 \mathrm{LF}$ en el contexto de la reunificación alemana proporcionaba el fundamento doctrinal para proceder a la derogación del art. $146 \mathrm{LF}$ a través del TU. Sin embargo, concluido el proceso de reunificación, el mantenimiento del art. 146 LF v.n. ${ }^{30}$ deviene inconstitucional ${ }^{31}$, dado que el único fundamento de validez del art. 146 en la antigua LF era la vía reunificadora-constituyente que ofrecía. Conseguida la reunificación sin necesidad de apelar al poder constituyente, decae su pertinencia, por lo que su mantenimiento en el nuevo texto constitucional (LF v.n.) colisiona directamente con el art. 79.3 LF v.n.

Aunque la argumentación comentada no carece de elegancia, desatiende el contenido propio del art. 146 LF v.n., cuya condición de vía para la unificación no agota el significado de su contenido ${ }^{32}$. El art. $146 \mathrm{LF}$ v.n. es la invocación para culminar la reunificación alemana -cualquiera que haya sido la vía seguida para ello- con una nueva Constitución de la Alemania unida. El art. 146 LF establece una relación entre la reunifi-

${ }^{29}$ Criterio sostenido por: Th. MAUnz, en MAUnz/DüRING, Grundgesetz Kommentar, art. 23; ISENSEE, J., op. cit., nota 4; TOMUSCHAT, Ch., "Deutschlands aktuelle Verfassungslage", en VVDStRL n. 49, Berlín, 1990.

30 Según el art. 4.6 del TU, el art. 146 LF queda como sigue: art. 146 LF v.n.: "Esta Ley Fundamental que, una vez alcanzada la unidad y libertad de Alemania, es válida para todo el pueblo alemán, perderá su validez el día que entre en vigor una Constitución acordada por la libre decisión del pueblo alemán", donde el párrafo en cursiva corresponde a la addenda introducida en el antiguo art. 146 por el art. 4.6 del TU.

${ }^{31}$ Criterio sostenido por: HuBA, H., "Das Grundgesetz als dauerhafte gesamtdeutsche Verfassung", Der Staat, vol. 30, 1991/3; ROELLECK, G., "Schwirichkeiten mit der Rechtseinheit nach der deutschen Wiedervereinigung", Neue Juristische Wochenschrift, 1991/11; ibdem, "Brauchen wir ein neues Grundgesetz?", en Neue Juristische Wochenschrift, 1991/39; KEMPEN, B., "Grundgesetz oder neue deutsche Verfassung?", en Neue Juristische Wochenschrift, 1991/15.

${ }_{32}$ Para el Tribunal Constitucional Federal, en su sentencia sobre el Partido Comunista alemán de 1956, el art. 146 LF expresaba claramente que sólo una Constitución libremente aprobada por el pueblo alemán podría ser considerada la decisión definitiva del futuro estatal de Alemania (STCF 5, 85, 127, cit. en WEIS, H., "Verfassungsrechtliche Fragen im Zusammenhang mit der Herstellung der staatlichen Einheut deutschlands", Archiv für öffentliches Recht, 1991/1, pág. 5). 
cación -por cualquier vía- y el poder constituyente ${ }^{33}$. El enunciado del art. $146 \mathrm{LF}$ contiene un doble mensaje: a) la LF tenía carácter provisional, no sólo porque el Estado que presidía estaba incompleto, sino porque aquella carecía de legitimación democrática originaria; b) la provisionalidad de la LF y, a su vez, la transitoriedad estatal alemana desaparecerá cuando, y sólo cuando, aquélla sea sustituida por la Constitución prevista en el art. 146 LF v.n.

Los dos artículos constitucionales ( 23 y 146 LF) estaban previstos para aspectos distintos de un mismo proceso. No es aceptable la aplicación del procedimiento de uno de ellos para los aspectos que correspondería regular al otro. De este modo resulta completamente inadecuado entender la "reunificación alemana" como un mero epifenómeno de las sucesivas incorporaciones que, al abrigo del art. 23 LF, puedan haber efectuado los distintos territorios alemanes. Una vez que las sucesivas incorporaciones territoriales cristaliza en una RFA cuya coincidencia con el "Deutscher Reich" de 1867 es la máxima posible, es decir, cuando las fronteras de la RFA se acerquen lo máximo permitido a las que tenía Alemania en diciembre de 1937, entonces ya no se puede seguir hablando de la RFA. Nos encontramos ya con la Alemania territorialmente reintegrada, en la que el art. 146 LF v.n. fundamenta su invocación al poder constituyente ${ }^{34}$.

La posibilidad de una utilización secuencial de los dos enunciados en los que la LF depositaba la responsabilidad de articular la reunificación alemana (integración territorial de hecho por vía del art. 23 LF y reconocimiento de derecho por la vía constituyente del art. $146 \mathrm{LF})^{35}$, fue descalificada en el "Congreso extraordinario de los Profesores alemanes de Derecho político", celebrado en Berlín en abril de 1990, como "tercera vía" inexistente para la $\mathrm{LF}^{36}$. En contra de la utilización combinada de

${ }_{33}$ Que la potestad constitucional entendida en el art. 146 LF es el poder constituyente - no el poder constituyente constiuido- es un lugar común del derecho constitucional alemán (ver SCHEUNER, U., op. cit.; MURSWIECK; D., "Die verfassungsgebende Gewalt nach dem GG für die BRD", 1978; ZuLEEG, M., "Rechtslage deutschlands", en DeNNINGER/RidDeR/SimON/STEIN (eds.), Kommentar zum GG für die $B R D$, Darmstadt, 1984, vol. I).

${ }^{34}$ Ver RöPER, E., "Notwendige Kooperation des bisherigen DDR-Länder in Vereinten deutschland", en Recht und Politik, 1990/3, pág. 142.

35 Posibilidad mantenida por varios autores: FroweIN, J. A. op. cit., nota 1; Rauschning, D., "Deutschlands aktuelle Verfassungslage», en Deutsche Verwaltungsblatt, 1990; HaBerLE, P., "Verfassungspolitik für die Freiheit und Einheit Deutschlands", en Juristische Zeitung, 1990; STOROST, U., "Das Ende der Ubergangszeit", en Der Staat, 1990/3.

${ }^{36}$ En palabras de J. ISENSEE, "la LF sólo contempla la permanencia de su validez (art. 23) o su desaparición (art. 146)" (ISENSEE, op. cit., nota 4). 
los arts. 23 y 146 LF para concluir la plena constitucionalización de la Alemania reunificada, se objetó que ello supondría completar la territorialidad alemana, a reserva de la inmediata decadencia de la norma bajo cuya cobertura se había realizado, dado que la aplicación del art. 146 LF conlleva la desaparición de la LF. Se produciría entonces, a juicio de estos críticos, una minoración ab initio de la fuerza normativa de la LF que, de su condición de instrumento para la reunificación, deviene un mecanismo de devaluación normativa de la propia $\mathrm{LF}^{37}$. Con esto se bloqueó una posibilidad, rápida y eficaz, de articular la nueva Constitución del pueblo alemán en el sentido del art. 146. Posibilidad con la que se conseguiría la desaparición de este incómodo artículo de la manera más conforme a la Constitución: por su cumplimiento, $y$, además, con un coste político razonablemente pequeño.

La conclusión del período transitorio - una vez el art. 23 LF ha aglutinado la complitud territorial alemana- marca el momento para la ejecución del art. 146, ya que la LF, como toda ley a plazo, sólo pretendía una vigencia temporal limitada. Aunque el carácter insuperable que hubiesen podido adquirir los hechos causantes de la transitoriedad $y$, por ende, de la provisionalidad de la norma constitucional encargada de cubrirla, podrían haber dotado a la LF de una duración ilimitada, lo cierto es que la LF ha sido siempre entendida como una norma provisional de vigencia limitada. La opinión doctrinal más autorizada coincidió, desde los primeros tiempos de la RFA, en el orden sucesorio de validez de las dos constituciones, la provisional LF y la definitiva, que, según art. $146 \mathrm{LF}$, la sustituiría ${ }^{38}$.

\section{Inderogabilidad del art. 146 LF n.v.}

En los debates parlamentarios para la aprobación del Tratado de Unificación (TU), el Gobierno federal y la mayoría parlamentaria que lo apoyaba nunca ocultaron su voluntad de deshacerse directamente del art. 146 LF v.a., por medio de una enmienda constitucional en el corres-

37 Ver el debate en el "Congreso extraordinario de los Profesores de Derecho Político" (VVDStRL n. 49, Berlín, 1990), donde ISENSEe defendió esta no muy afortunada objeción.

${ }_{33}$ Ver ABENDROTH, W., "Deutsche Einheit und europäische Integration in der Praambel des Grungesetzes der Bundesrepublik Deutschland", en Europa-Archiv, 1951; Немке, W., Die verfassungsgebende Gewalt des deutschen Volkes, 1957. 
pondiente artículo del TU que, a estos efectos, debería ser aprobado por mayoría de $2 / 3$ de cada una de las Cámaras legislativas. Obviamente, esta vía por la que se pretendía poner fin a la provisionalidad de la LF, una vez concluida la transitoriedad política y territorial, era sin duda la más cómoda y rápida, aunque también la más cuestionable jurídicamente. La pretensión de someter el art. 146 LF v.a. al poder de reforma de la LF contenido en el art. 79.1 y 2 LF, no encajaba en la estructura normativa que el art. 146 LF v.a. instauraba en la LF. Este artículo, con independencia de su no inclusión entre las materias excepcionadas al poder de reforma del art. 79.3 LF, constituye un límite implícito a dicho poder de reforma. Es un límite, porque su contenido, como veremos, es indisponible para el poder de revisión constitucional. Es implícito, porque no se encuentra entre las excepciones a la potestad de enmienda constitucional, recogidas en el art. $79.3 \mathrm{LF}$.

Ciertamente, la doctrina en torno a los límites implícitos a la revisión constitucional no es algo firme y claramente establecido. Pero con independencia de la diversidad de opiniones, existe unanimidad en rechazar la disponibilidad absoluta sobre la Constitución por parte de los órganos constituidos ${ }^{39}$. Siempre existirán aspectos implícitamente irreformables en toda Constitución ${ }^{40}$, ya que un contenido inmutable y permanente es inherente al propio concepto de Constitución. En esta línea de pensamiento es posible sostener incluso la existencia de límites al propio poder constituyente. Límites que, en este caso, sólo pueden ser implícitos, "los derechos preestatales y supraestatales se encuentran sustraídos a su capacidad de decisión ${ }^{41}$. Más discutible es ya asimilar este contenido indisponible a los rasgos identificativos del Estado, con lo que las leyes de revisión constitucional tendrían un límite implícito en la estructura normativa de la Constitución, conformadora de la institucionalidad del Estado que preside ${ }^{42}$.

39 Incluso BISCARETTI DI RUFFIA, que ni siquiera acepta cláusulas de intangibilidad ni excepciones a la revisión constitucional, entiende que la disponibilidad de la Constitución tiene, para el legislador constitucional, la limitación del derecho vigente (ver Biscaretti dI Ruffia, Derecho Constitucional, Madrid, 1973, págs. 279-80). Derecho vigente en el que habrán de incluirse, necesariamente, los principios y valores que, desde la Constitución, informan el ordenamiento jurídico de cada período.

${ }_{40}$ Aspectos "que no deban estar necesariamente expresados en disposiciones o instituciones concretas, sino que rigen como "implícitos", "inmanentes" o "inherentes" a la Constitución" (LoewensteIn, K., Teoría de la Constitución, Barcelona, 1979, pág. 189.

41 MaUnz, Th., "Die verfassungsgebende Gewalt im Grundgesetz", en KuRz, H. (ed.), Volkssouveränität und Staatssouveränität, Darmstadt, 1970, pág. 313.

${ }_{42}$ Según MORTATI, la inferioridad de las leyes de revisión constitucional respecto de la Constitución iimplica para aquéllas la obligación udi rispettare i principi essenziali del tipo di stato quale risulta dall'ordinamento in atto" (MORTATI, C., Ins- 
La LF se pronuncia por un contenido irreformable, recogido en su art. 79.3. Es un rasgo tanto más sorprendente cuanto que parece contradecir la condición provisional con la que la LF se entiende a sí misma ${ }^{43}$. La contradicción es, sin embargo, sólo aparente. Que la LF se entienda a sí misma como provisional, no empece para que, durante su período de vigencia, entienda irreformables determinados enunciados de su contenido. Ello sólo pretende proteger el núcleo constitucional frente al poder de reforma, no acotar un bloque constitucional eterno e inmutable. Pretensión que sí sería contradictoria con la provisionalidad originaria del texto en la que se recoge. Es más, podría afirmarse - como hace SCHEUNER- que la cláusula de inderogabilidad del art. 79.3 LF y el efecto de rigidez absoluta que, sobre el núcleo constitucional en ella referido, produce, resulta sólo soportable debido a que, pro futuro, la LF abre la posibilidad de su "revisión total» a través del art. $146 \mathrm{LF}^{44}$. Para los constituyentes de 1949, establecer la intangibilidad de partes de la LF en su art. 79.3, no era contradictorio con la provisionalidad del documento en el que se establecía, toda vez que dicha intangibilidad no vinculaba al poder constituyente invocado en el art. $146 \mathrm{LF}^{45}$.

En cuanto a la cuestión de la reforma del art. 146 LF, la situación es similar a la que plantea la irreformabilidad implícita de los artículos reguladores de la reforma constitucional. En el caso de la LF, su reforma se rige por el procedimiento establecido en los apartados 1 y 2 del art. 79, mientras que el apartado 3 de dicho artículo contiene las excepciones de reformabilidad, sin que en él se incluya el propio art. 79 LF. Sin embargo, no es posible admitir que el art. $79 \mathrm{LF}$ quedase sometido al régimen general de reforma que él mismo establece. Admitir lo contrario supondría la posibilidad de aniquilar el propio art. $79 \mathrm{LF}$ o modificar sustancialmente sus condiciones de aplicación y, con ello, la propia cláusula de intangibilidad recogida en el apartado 3 de dicho artículo. Afirmar la posibilidad de reforma de aquellos artículos que regulan los procedimientos de

tituzioni di diritto pubblico, Padova, 1976, vol. II, pág. 1242). Opinión que no es compartida por BISCARETTI, para quien la condición "constituida" de los órganos de reforma no puede impedir al Estado que conforman, desarrollarse y modificarse como oportunamente entienda, "si bien moviéndose siempre en el ámbito del derecho vigente" (BISCARETTI DI RUFFIA, op. cit., nota 39, págs. 279-80)

${ }^{43}$ Ver intervención de ISENSEE en la sesión de debate de la "Asociación alemana para Asuntos Parlamentarios», en Zeitschrift für Parlamentsfragen, 1990/2. También SCHEUNER, "Art. 146 GG und das Problem der verfassungsgebenden Gewalt" (DÖV, 1953), reimpreso en KURz, H., Volkssouveränität und Staatssouveränität, Darmstadt, 1970, págs. 294-95).

44 Ver SCHEUner, U., op. cit., nota 43, págs. 294-95.

15 La objeción respecto de la obviedad de la ilimitación del poder constituyente fue en su día rebatida ya por C. ScHMid (ver supra, pág. 7, nota 20 ). 
reforma constitucional equivaldría a dejar abierto el proceso constituyente y, por tanto, a carecer de Constitución. Ciertamente, desde un positivismo rígido no habría objeción alguna a la reforma del art. 79 LF, dado que, careciendo de cláusula de reflexibilidad, nada impediría su modificación o, incluso, derogación, por medio de una ley de reforma constitucional. Pero aunque el derecho constitucional positivo no lo prohíba, sí lo impide la propia lógica normativa, de la que se sigue la irreformabilidad tanto de la cláusula procedimental de reforma como de la que enumera los contenidos irreformables ${ }^{46}$.

La irreformabilidad afecta, por lógica normativa, a los artículos que establecen los procedimientos y condiciones de reforma de la Constitución. Pero, por la misma lógica, la irreformabilidad habría de hacerse extensiva a aquellas normas constitucionales establecedoras de las condiciones de validez y vigencia de la propia Constitución ${ }^{47}$. El artículo que enuncia la condición provisional de una Constitución, juntamente con el procedimiento para que ésta deje de serlo, no puede quedar a disposición del poder de reforma de dicha Constitución. En caso contrario, supondría que la Constitución podría acceder a una condición nueva, sin someterse al único procedimiento establecido para ello, que es el del art. 146 LF. En este sentido, la eliminación del art. 146 LF sería algo más que una reforma constitucional. Sería acceder a la condición constitucional prevista en el art. $146 \mathrm{LF}$, pero por el procedimiento del art. $79 \mathrm{LF}$, lo que equivaldría a un fraude de Constitución. Sería el acto de un poder constituido que suplanta la naturaleza de un acto constituyente ${ }^{48}$.

Al contener el art. $146 \mathrm{LF}$ un procedimiento de "reforma total» de la LF, dicha reforma no se vería limitada ni por las excepciones de reformabilidad del art. 79.3 LF, ni tampoco por la irreformabilidad implícita del

46 Ver MAUnz/DüRING, Grundgesetz Kommentar, art. 79.

${ }_{47}$ Con el agravante, en el presente caso, de que la reforma del art. $146 \mathrm{LF}$ convertiría a la cláusula de intangibilidad del art. 79.3 LF en una auténtica declaración de eternidad, la modificación. de cuyo menor aspecto (y el art. 79.3 LF incluye también aspectos relativamente menores del ordenamiento constitucional alemán) sólo sería posible a través de una irrupción "revolucionaria» del poder constituyente.

${ }_{48}$ Toda Constitución, con independencia de su origen y forma de elaboración, vinculó siempre al poder constituido, pero nunca al poder constituyente (ver MAUNZ, Th., "Die verfassungsgebende Gewalt im Grundgesetz», DÖV, 1953, reimpreso en KURZ, H., Volkssouveränität und Staatssouveränität, Darmstadt, 1970, pág. 321). Por tanto, el art. $79 \mathrm{LF}$, en tanto que configuración de un poder constituido, no puede modificar al art. 146 LF que, aunque formalmente, es parte de la Constitución, materialmente es la expresión del poder constituyente. 
propio art. $79 \mathrm{LF}^{49}$. La justificación de esta falta de reciprocidad entre la eficacia de ambos artículos deriva de la diferente cualidad de los poderes contenidos en ambos artículos. Por un lado, el poder de reforma constitucional del art. 79 LF, que es el "poder constituyente constituido" o poder susceptible de introducir las reformas posibles en el marco preexistente de la LF, cuya sustancia permanecerá inalterada. Por el otro, el "poder constituyente" originario del art. $146 \mathrm{LF}$, el cual no podrá verse limitado por la Constitución, en la que se encuentra recogido, $y$, por tanto, tampoco por ninguno de sus artículos. Cierto que, como ya dijimos ${ }^{50}$, existen límites al poder constituyente, pero derivan de la equidad natural y de la naturaleza axiológica del derecho, pero nunca del derecho positivo.

\section{La tramitación parlamentaria del Tratado de Unificación (TU) y la versión final del art. 146 LF}

El proceso reunificador alemán se ha efectuado bajo la cobertura de la LF, a la que se ha querido ver convertida en la Constitución de la Alemania reunificada, una vez eliminados de su texto aquellos pasajes alusivos a la incomplitud de la RFA y de su estatuto jurídico (LF), como expresión del pueblo y nación alemanes ${ }^{51}$. En cuanto al art. 146 LF, la solución adoptada - vigente hasta el momento - ha sido la de mantenerlo, aunque proveyéndole de un añadido que, en sentido riguroso, no supone modificación de su contenido. La solución adoptada al problema planteado por el art. 146 LF ha sido, de todas las posibles, quizá la más desa-

49 Cualquiera que sea el procedimiento seguido para la elaboración de la Constitución prevista en el art. 146 LF, siempre será adecuada a derecho, aunque no se ajuste ni al procedimiento establecido en el 79.1 y 2 LF, ni tampoco respete la irreformabilidad de las materias del art. 79.3 LF (ver ZuLEEG, M., "Rechtslage Deutschlands", en DenNingeR/RIDDER/Simon/Stein, eds., Kommentar zum Grundgesetz für die Bundesrepublik Deutschland, Darmstadt, 1984, vol. I, pág. 164). El procedimiento previsto en el art. 79 LF no puede derogar al art. 146 LF, pero la eficacia de éste último no sólo puede modificar aquél, sino que puede actuar como si el art. 79 LF no existiera.

so Ver supra, nota 41.

51 Ver intervenciones de: A. Renger (Vipta. de la Dieta Federal) en “Debate de la Asociación alemana para Asuntos parlamentarios"; J. ISENSEE, en "Congreso extraordinario de la Profesores alemanes de Derecho político"; K. KINKEL, Secretario de Estado del M. $\cong$ Federal de Justicia, en «Simposio conjunto del Consejo Federal y de la Sociedad alemana de Legislación". Se pretendió hacer de la LF la Constitución alemana, una vez eliminados de su texto aquellos pasajes incompatibles con la situación creada después de la adhesión de la RDA. 
fortunada. Del abanico de posibilidades de actuar sobre y a través del art. 146 LF, obviamente la más ajustada al propio art. 146 LF y a la intención de los creadores de la LF, hubiese sido su cumplimiento: la creación de una nueva Constitución, sancionada por un referéndum de todo el pueblo alemán.

Descartada esta opción - comprensiblemente, si por ella se entendía un procedimiento constituyente que fuese coincidente con el proceso unificador de los dos Estados alemanes-, no resulta ya tan comprensible rechazarla, como vía de conclusión constitucional, una vez operada la reunificación territorial alemana al abrigo del art. 23 LF. Parece entonces desacertado el rechazo inicial a una "tercera vía", resultante de la aplicación sucesiva de los arts. 23 y 146 LF. Precisamente, es una de las variantes de la descartada "tercera vía» la que, como veremos, aporta una solución al problema planteado por el art. 146 LF, y a un coste político razonablemente adecuado al fundamento legitimador que proporcionaría al definitivo estatuto constitucional alemán.

En lugar de actuar de acuerdo a una combinación de las vías constitucionales previstas por los arts. 23 y 146 LF, el legislador ha optado por conservar el art. 146 LF en la Constitución actual alemana. En este sentido, el aptdo. 6 del art. 4 del TU hace una addenda jurídicamente irrelevante para el contenido sustancial del art. $146 \mathrm{LF}$. El texto de la nueva formulación reza: "Esta Ley Fundamental - la cual, concluida la unidad y libertad de Alemania, es válida para todo el pueblo alemán- perderá su validez el día que entre en vigor una Constitución acordada por la libre decisión del pueblo alemán", donde el subrayado es el texto de la addenda efectuada al texto originario del art. 146 LF. Como puede comprobarse, la parte añadida al art. 146 LF por el art. 4.6 del TU no produce modificación sustancial alguna al contenido original del artículo ${ }^{52}$. El porqué se ha conservado en la Constitución alemana o LF v.n. (versión nueva) el enunciado, sustancialmente inalterado, del art. 146 LF v.a. (versión antigua), no tiene una explicación clara. Una decisión de semejante imprecisión técnica asombra en un constitucionalismo tan tecnificado como el alemán. El mantenimiento sustancialmente inalterado del antiguo enunciado implica la continuación de la naturaleza provisional de la LF. La carga de incertidumbre que proyecta es un factor latente de inquietud en el funcionamiento institucional. La solución adoptada expresa y perpetúa la indecisión que atenazó a la mayoría conservadora de gobierno. La insa-

52 El enunciado añadido constituye, en sí mismo, una obviedad: La validez de la LF para todo el pueblo alemán es el resultado automático de la incorporación (ver HuBA, H., "Das GG als dauerhafte gesammtdeutsche Verfassung", en Der Staat, 1991/3, pág. 373). 
tisfacción general, originada por la solución dada al problema por el art. 4.6 TU, la expresa sinceramente O. KIMMNICH: "Todos nosotros estamos perplejos frente a este precepto. Estamos todos de acuerdo en que [el art. 146 v.n.] no debería ser aplicado, en que carece de función: es un desacierto, es superfluon" ${ }^{53}$.

EI TU fue el instrumento jurídico utilizado para operar en la LF aquellas modificaciones que la adaptasen a la nueva realidad política y territorial alemana, una vez producida la adhesión de la RDA a la RFA. En este sentido, el art. 2 TU establece que la capital federal será Berlín, aunque la decisión sobre la sede del Parlamento y Gobierno federales la pospone para después de la reunificación. El art. 4.3 TU, donde se establece el número de votos que corresponden a cada uno de los 5 nuevos Länder en el Consejo Federal. El art. 7 TU, que contiene diversas disposiciones sobre financiación de los nuevos Länder. Art. 45.2 TU, que prevé la vigencia del Tratado después de efectuada la adhesión. Disposición necesaria, toda vez que el TU contiene plazos de adaptación legislativa en los nuevos Länder, lo que implica períodos de inaplicación del derecho federal e incluso de la LF a los nuevos territorios. Pero la modificación más importante introducida en la LF se contiene en el art. 4.1 TU, derogatorio del art. $23 \mathrm{LF}$, con lo que se cierra la posibilidad de futuras incorporaciones territoriales, afirmando el carácter definitivo de las fronteras exteriores de la Alemania reunificada.

En cuanto al art. 146 LF v.n., responde a la incidencia de dos factores, uno de hermenéutica constitucional y otro de derecho parlamentario. El primero de ellos consistía en la interpretación mantenida por la mayoría parlamentaria de gobierno (conservadores y liberales), según la cual el art. $146 \mathrm{LF}$ se encontraba sometido al poder de reforma constitucional del art. 79.1 y 2 LF. El segundo apuntaba entonces a la necesidad de conseguir - de acuerdo con el art. 79.2 LF- la mayoria cualificada de 2/3 en la Dieta y Consejo Federales, para proceder a la derogación directa del art. 146 LF, como pretendía el Gobierno federal y la coalición de partidos que lo apoyaba. Mayoría cualificada que los partidos del gobierno no podian alcanzar, debido a que el grupo parlamentario de Los Verdes exigía el cumplimiento literal del art. 146 LF, y el grupo socialdemócrata no había renunciado a un referéndum popular, cualquiera que fuese el destino del art. 146 LF $^{54}$.

53 Кıмmnich, O., en Stern, K. (ed.), Deutsche Wiedervereinigung, vol. I, Eigentum - Neue Verfassung - Finanzverfassung, 1991, pág. 111.

${ }_{54}$ El Partido Socialdemócrata propugnaba que la modificación por $2 / 3$ de la LF fuese, no obstante, seguida de un referéndum (ver SACHS, M., "Das GG im vereinten Deutschland - endgültiye Verfassung oder Dauerprovisorium?", Juristische Schulung, dic. 1991, pág. 989). 
La coalición de gobierno y, especialmente, los conservadores siempre fueron partidarios de la derogación directa del art. 146 LF. En el debate sobre el TU lo expuso con claridad el ministro federal de Interior SCHAUBLE, para quien la derogación directa del art. 146 LF era algo jurídicamente inobjetable. La posición contraria era sostenida por el grupo parlamentario de Los Verdes, para el que, en buena lógica interpretativa, la LF contenia, y en la actualidad sigue conteniendo, dos posibilidades:

- La reforma parcial de su texto por mayoría cualificada de $2 / 3$ de la Dieta y el Consejo federales.

- La revisión total o, lo que es lo mismo, la elaboración de una nueva Constitución, por mayoría simple de cada una de los dos Cámaras, y el referéndum popular sobre el texto constitucional.

La barrera de la mayoría parlamentaria necesaria para derogar el art. 146 LF obligó a los partidos del gobierno a conservarlo en el texto de la LF posterior a la reunificación alemana. Dentro de esta estrategia $y$, como mal menor, buscaron consolidar la interpretación del art. 146 LF v.n., en el sentido de que la potestad de revisión total de la LF en él invocada, también se encontraría sometida a los imperativos formales y materiales del art. $79 \mathrm{LF}^{55}$. En esta propuesta interpretativa pro futuro, el Gobierno federal coincidía con el sector doctrinal importante de constitucionalistas ${ }^{56}$. De acuerdo con esta posición doctrinal, el referéndum constitucional contenido en el art. 146 LF habrá de versar sobre un proyecto de Constitución, previamente aprobado por mayoría de $2 / 3$ de ca-

55 Como expuso el diputado democristiano RuTtGers: "Querer desde aquí transitar hacia una revisión total por mayoría simple -como todavía hemos escuchado esta mañana-, no es aceptable para mí y mi grupo parlamentario" (cit. en WIEDERIN, E., "Die Verfassungsgebung im wiedervereigniten Deutschland", Archiv des öffentlichen Rechts, 1992/3, pág. 435).

56 Sector doctrinal en el que se encuentran WEIS, H., "Verfassungsrechtliche Fragen im Zusammenhang mit der Herstellung der staatlichen Einheit Deutschlands", en Archiv des öffentlichen Rechts, 1991/1; KEIN, E., "Bundesstaatlichkeit im vereinten Deutschland", en Internationale Juristen-Komission, 1991; KIRCHHOF, P., "Der Auftrag zur Rechtseinheit im vereinten Deutschland", en Internationale Juristen-Komission, 1991; HESSE, K., Grundzüge des Verfassungsrechts der Bundesrepublik Deutschland, 18. ed. 1991; BLUMENWITZ, D., "Wie offen ist die Verfassungsfrage nach der Herstellung der staatlichen Einheit Deutschlands?", en Aus Politik und Zeitgeschichte, Suplemento semanal de Das Parlament, 29-11-1991; Mangoldt/Klein/Campenhausen, Das Bonner Grundgesetz. Kommentar, 3. $\mathrm{a}$ ed., 1991, vol. 14, art. 146; IsEnSEe, J., en SteRn (ed.), Deutsche Wiedervereinigung, vol. I, Eigentum - Neue Verfassung - Finanzverfassung, 1991; ScHOLz, R., "Art. 146 LF", en MaUnz/DüRING, Grundgesetz. Kommentar. 
da órgano legislativo (art. 79.2 LF), cuyo contenido habrá de respetar los límites materiales prescritos en el art. 79.3 LF. Posición que se fundamenta en el principio de interpretación conforme a Constitución que, en este caso concreto, significa interpretar el art. 146 LF en un sentido acorde al art. 79 LF. En apoyo de esta frágil fundamentación se aduce que el legislador constitucional no hizo uso en 1990 de la invocación del art. $146 \mathrm{LF}$, justo cuando se produjeron los supuestos habilitantes para ello. Inacción cuyo sentido es haber desvinculado el art. $146 \mathrm{LF}$ de su contexto inicial, dotándole de una vigencia independiente de aquél. La addenda contenida en el art. 146 LF v.n. significaría un claro pronunciamiento en favor de esta tesis ${ }^{57}$, cuya consecuencia sería que, pro futuro, el cumplimiento del art. 146 LF v.n. quedará vinculado a las exigencias formales y materiales del art. 79 LF.

Para el Gobierno federal y los partidos que sustentaban su mayoría parlamentaria, la preocupación esencial consistía en el potencial, latente en el art. 146 LF v.n., para desencadenar un proceso constituyente por mayoría simple de los órganos legislativos, sin que además dicha iniciativa se encontrase obligada por la cláusula de inderogabilidad del art. 79.3 LF. De ahí el empeño del grupo parlamentario conservador en la Dieta Federal por condicionar el art. 146 LF v.n. a su vinculación al art. 79 LF. En el Memorándum sobre el TU, el Gobierno Federal resaltó que la nueva versión del. art. 146 LF confirmaba "la realización de la unidad alemana bajo la vigencia continuada de la LF, entendida como ordenamiento jurídico fundamental de todo el pueblo alemán ${ }^{58}$, con lo que en adelante las reformas constitucionales precisarían siempre de una mayoría parlamentaria de $2 / 3$ de cada una de las Cámaras. Pronunciamiento que, a su vez, no dice nada nuevo, limitándose a remachar una obviedad de derecho constitucional: que la reforma de la LF, en su versión actual, sigue estando sometida a las condiciones enunciadas en los distintos apartados del art. 79 LF. Es una afirmación innecesaria, dado que se entiende por sí misma. Ciertamente que, en el caso de entender el art. 146 LF como disponible para el poder de reforma constitucional - algo que, como vimos más arriba en el apartado II.-3), no resulta aceptable para un adecuado entendimiento de la relación de poder existente entre el art. 79 y el art. 146 de la LF-, su derogación habrá de operarse necesariamente de acuerdo con lo previsto en el art. 79 LF. Pero esta obviedad no significa que el poder invocado por el art. 146 LF v.n. haya de someter su ejercicio a las mismas limitaciones a que se ve constreñido

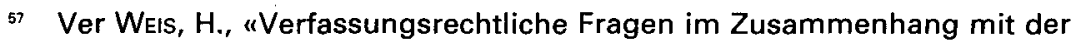
Herstellung der staatlichen Einheit Deutschlands", en Archiv des öffentlichen Rechts, 1991/1, págs. 29-30.

58 Cit. en Wiederin, E., op. cit., en nota 55, pág. 433. 
el poder de enmienda constitucional del art. 79 LF. Por el contrario, ya el TCF alemán expresó que cualquier actuación encaminada a realizar la Constitución invocada en el art. 146 LF sería siempre "acorde a derecho" ("rechtsmässig»), incluso cuando no se atuviese a los procedimientos previstos en la LF ${ }^{59}$.

Con independencia entonces de cuál pueda ser la estrategia de los distintos grupos parlamentarios, los efectos y las consecuencias del art. 146 LF n.v. derivarán del significado que objetivamente tenga su contenido. Por ello mismo, la pretensión del grupo parlamentario conservador en la Dieta Federal de que el legislador constituyente del art. 146 LF n.v. quede vinculado, en el ejercicio de su potestad, a las limitaciones establecidas en el art. 79.2 y $3 \mathrm{LF}$, carece de fundamento en el texto constitucional. La constitucionalización definitiva de Alemania sigue siendo ahora como antes un proceso que se encuentra liberado de las ataduras y limitaciones del art. $79 \mathrm{LF}^{60}$. Los temores de la coalición de gobierno se encuentran entonces confirmados, ya que el art. 146 LF n.v. deja a disposición de una mayoria parlamentaria simple aquel núcleo constitucional que el art. 79.3 LF quería mantener al margen de toda reforma.

\section{Propuesta de solución al problema del art. 146 LF n.v.}

La situación constitucional actual, planteada por el enunciado del art. 146 LF n.v. y el estigma de provisionalidad con que afecta a la LF, sólo consiente como solución aceptable la supresión del art. 146 LF n.v. Supresión que habrá de efectuarse con el menor coste político posible, sabiendo que no es viable su derogación directa por vía de enmienda constitucional por mayoría de $2 / 3$ de cada Cámara legislativa, y ello no sólo por la imposibilidad actual para mayorías cualificadas, sino porque además este procedimiento adolecería de una razonable objeción de inconstitucionalidad, susceptible de fundamentar el correspondiente recurso de inconstitucionalidad ante el TCF alemán.

Sin embargo, no sería necesario adoptar un procedimiento tan drástico como la derogación directa del precepto -técnicamente tan

59 STCF 5, 85, 131, cit. en ZuLEeG, M., "Rechtslage Deutschlands», en DeNNINGER/RIDDER/SIMON/STEIN (eds.), Kommentar zum GG für die BRD, 2 vols., Darmstadt, 1984, vol. I, pág. 164. pág. 989.

60 Ver: WIEDERIN, E., op. cit., nota 55, pág. 437; SACHS, M., op. cit., nota 54, 
cuestionable y tan inconcluso en cuanto a su resultado- cuando existe una vía de actuación, técnica y constitucionalmente inobjetable, y cuya rapidez y sencillez no comprometería seriamente la estabilidad del funcionamiento institucional.

Partiendo de la premisa sostenida por el grupo parlamentario de Los Verdes, según la cual la potestad constitucional contenida en el art. 146 LF n.v. puede ejercitarse por mayoría simple de los órganos legislativos, la solución del problema no ofrece mayores dificultades.

Que la potestad enunciada en el art. 146 LF n.v. puede ejercerse por mayoría simple de las cámaras legislativas, es lógicamente deducible de los enunciados de los dos artículos (79 y 146) en el mismo texto constitucional. Si la LF prescribe en el art. 79.3 un núcleo material irreformable $y$, simultáneamente, prevé su revisión total en el art. 146, es evidente que éste último ha de entenderse como una excepción a la eficacia de aquél, excepción que afecta tanto a las prescripciones formales del art. 79.2 como a las limitaciones materiales del art. 79.3. Todo indica entonces que el art. $146 \mathrm{LF}$ introduce una potestad constitucional, derogatoria de la $L F$, independiente de la exigencias procedimentales y de las limitaciones materiales del art. 79.2 y 3 LF. Por otro lado, el art. 146 LF n.v. tiene el mismo significado que tenía en la antigua LF, inmodificado sustancialmente por la addenda introducida en él por el TU. Significado consistente en que la derogación de la LF como un todo depende, según el art. 146, de una nueva Constitución, con independencia de que su texto sea idéntico al de la LF, exceptuado naturalmente el propio art. $146 \mathrm{LF}^{61}$.

Por consiguiente: 1) la potestad constituyente invocada en el art. 146 LF n.v. puede iniciarse por mayoría simple del Parlamento o, lo que es lo mismo, el proyecto de Constitución, derogatorio de la LF, que se presentaría a referéndum popular, puede ser aprobado por la mayoría simple de cada uno de los órganos legislativos federales; 2) el proyecto de Constitución, aprobado por la mayoría simple de cada una de las dos Cámaras legislativas, puede ser coincidente con el texto de la LF, exceptuado el art. 146, que habría desaparecido del proyecto constitucional presentado a referéndum.

A su vez, el referéndum constitucional, subsiguiente a la supresión del art. 146 LF, cumpliría -en el caso de un resultado positivo- - dos funciones:

61 Ver: Murswieck, D., Die verfassungsgewende Gewalt nach dem GG für die BRD, 1978, pág. 101; STEIN, E., Staatsrecht," 13. ed., 1991, pág. 334. 
1. Sancionaría definitivamente la supresión del art. 146 LF.

2. Aprobaría el texto de la LF (exceptuado su art. 146, que habría desaparecido), elevándolo con su pronunciamiento a la condición de verdadera Constitución alemana.

La supresión del art. 146 LF quedaría así legitimada, debido a que el acto de su supresión es, simultáneamente, la aplicación de su contenido: el proyecto constitucional que se presenta a referéndum es precisamente aquella Constitución invocada por el propio art. 146 como derogatoria de la LF. La supresión del art. 146 LF por vía de su aplicación no sólo es constitucionalmente posible ${ }^{62}$, sino obligada, siempre que se respete el procedimiento previsto en el art. 146, es decir, siempre que a su supresión suceda un referéndum del pueblo alemán.

Por otro lado, un resultado negativo del referéndum no supondría cambio jurídicamente reseñable para la subsiguiente validez de la $\mathrm{LF}^{63}$, si prescindimos del menoscabo de legitimidad que semejante resultado acarrearía.

63 Ver WIEDERIN, E., ibidem, pág. 444. 